\title{
Continuum de causatividad en griego antiguo: los verbos de influencia ${ }^{1}$
}

\author{
M. a Dolores Jiménez López \\ Universidad de Alcalá de Henares \\ Departamento de Filología \\ mdolores.jimenez@uah.es
}

Recibido: 25 de noviembre de 2010

Aceptado: 15 de diciembre de 2010

\begin{abstract}
RESUMEN

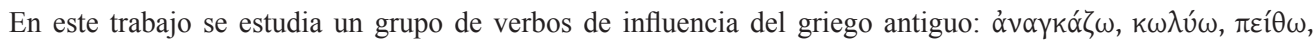
$\kappa \varepsilon \lambda \varepsilon u ́ \omega, \alpha i \imath \varepsilon ́ \omega, ~ \varepsilon a ́ \alpha \omega$. Como verbos causativos que son, presentan todos ellos características coincidentes, pero también hay aspectos sintácticos y semánticos en que difieren. El comportamiento específico de cada verbo depende de diversos factores que se estudian aquí y que permiten situar estos predicados en un continuum de causatividad, que va de los verbos implicativos a los no implicativos.
\end{abstract}

Palabras clave: verbos de influencia, verbos manipulativos, verbos causativos, verbos implicativos, sintaxis del griego antiguo.

\begin{abstract}

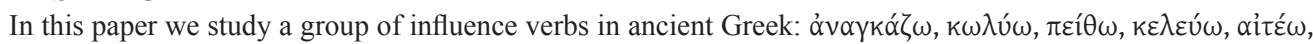
$\xi \dot{\varepsilon} \alpha \omega$. As causative verbs, all of them present similar features, but there are also syntactic and semantic aspects in which they differ. The specific behaviour of each verb depends on various factors that are studied here and that allow to place these predicates in a causative continuum, ranging from the implicative verbs to the nonimplicative.
\end{abstract}

Key words: influence verbs, manipulation verbs, causative verbs, implicative verbs, syntax of ancient Greek.

\section{INTRODUCCIÓN}

Es práctica tradicional en la sintaxis griega delimitar grupos de verbos a los que, dada su proximidad semántica, se les supone un comportamiento sintáctico similar. Pues bien, existe en griego antiguo un conjunto de predicados cuyo contenido

\footnotetext{
${ }^{1}$ Este trabajo forma parte del Proyecto de Investigación de la D.G.I. Rección y complementación verbal en griego y latin (II): verbos de proceso, actividad y causativos (FFI2009-13402-C04-02). Agradezco sus comentarios y sugerencias a todos los miembros del Proyecto, en una de cuyas sesiones de trabajo se presentó y discutió una primera versión.
} 
semántico ha permitido etiquetarlos como verbos de orden ( $\kappa \varepsilon \lambda \varepsilon v ́ \omega)$, de prohibición

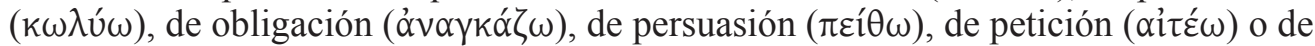
permisión ( $\varepsilon_{\alpha} \alpha$ ), y que en las clasificaciones más genéricas fluctúan entre los verbos de lengua y los de voluntad. En realidad, todos ellos tienen en común su condición de verbos causativos, en la medida en que expresan que una entidad ejerce su influencia sobre otra para que esta segunda haga o no haga algo. Este tipo de verbos, que han recibido denominaciones diversas - verbos manipulativos (Givón, 2001: I,151 ss./II, 41 ss.), verbos de actitud (Cano Aguilar, 1987: 136), verbos de influencia (Campos, 1999: 1535), etc.- están insuficientemente estudiados en griego antiguo, ya que no se ha tenido en cuenta este rasgo de causatividad que los condiciona semántica y sintácticamente.

En trabajos anteriores (Jiménez, 2003; 2007) he abordado el análisis de algunos de es-

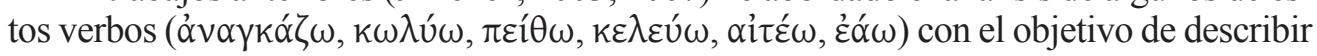
sus marcos predicativos: se definieron sus estructuras sintácticas en el ático de época clásica y se puso de manifiesto, por un lado, características comunes entre todos ellos, que los diferencian de los verbos de lengua y los de voluntad con los que tradicionalmente se han puesto en relación, y, por otro lado, rasgos distintivos entre unos y otros.

Los verbos estudiados expresan una causación del tipo que se ha llamado indirecta (Shibatani \& Pardeshi, 2002), en consonancia con su estructura sintáctica triargumental $^{2}$, que puede sintetizarse en el esquema de complementación de (1) y que ilustro con los ejemplos de (2):

(1) Verbo de influencia: $\left[\mathrm{x}_{1}\right]_{\text {Actor (causante) }}\left[\mathrm{x}_{2}\right]_{\text {Afectado (causado) }}\left[\mathrm{x}_{3}\right]_{\text {Efficiendum }}$

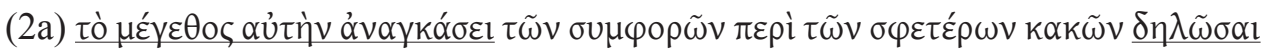

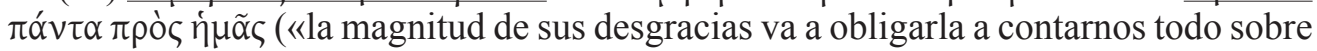
sus males», Lys. 32.11)

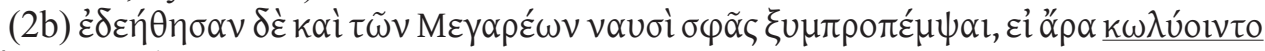

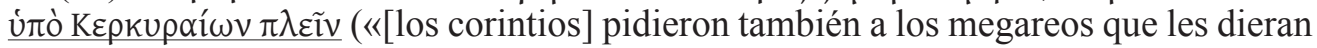
escolta con sus naves, por si acaso se veían impedidos por los corcireos para navegar», Th. 1.27.2)

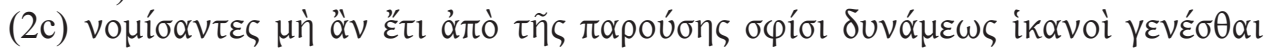

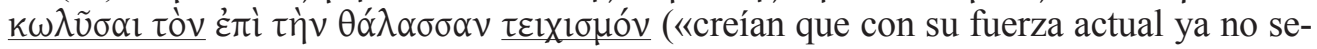
rían capaces de impedir la construcción de un muro hasta el mar», Th. 6.102.4)

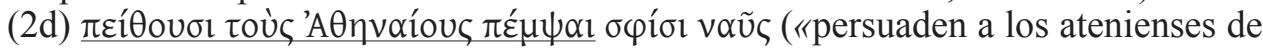
que les envíen naves», Th. 3.86.3)

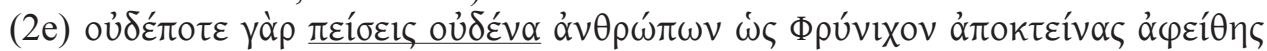

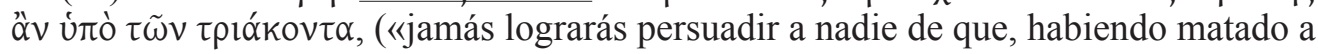
Frínico, habrías sido puesto en libertad por los Treinta», Lys. 13.75)

${ }^{2}$ La causación directa, que presentan muchos verbos transitivos (tipo $A$ mata a $B$ ), implica, por su parte, dos participantes: un causante Agente y un causado Afectado; el cumplimiento del evento causado depende por completo de la acción del causante y el causado no tiene ningún rasgo agentivo, por lo que normalmente la actividad del causante y el evento causado coinciden en el tiempo y en el espacio (Shibatani-Pardeshi, 2002: 89 ss.). 


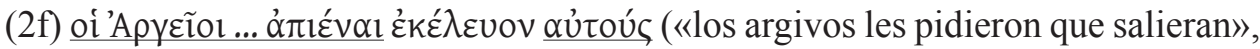
Th. 5.61.1)

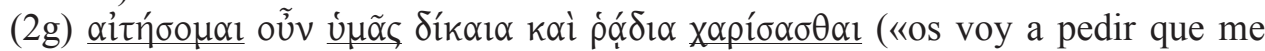
concedáis un favor justo y fácil», Lys. 19.2)

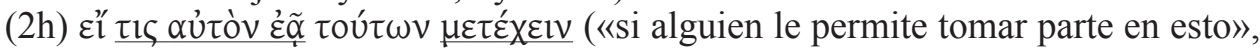
Lys. 26.3)

En efecto, estos verbos prevén un primer argumento que define una entidad que en las construcciones causativas suele denominarse causante (su acción tiende a desencadenar un determinado evento) y desempeña la macrofunción Actor (Dowty, 1991; Van Valin \& LaPolla, 1997:13 ss.): generalmente se trata de una entidad humana, por lo que su función semántica (FS) se concreta como un Agente protítipico (2b-h), pero algunos verbos admiten también ocasionalmente un referente no humano, como en (2a). Este argumento desempeña en la diátesis activa la función sintáctica de Sujeto y en pasiva, como es normal en griego, se presenta como complemento Agente bajo la forma de sintagma preposicional $(2 \mathrm{~b})$.

Un segundo argumento refiere una entidad siempre humana, que suele llamarse causado o manipulado y que en nuestros verbos se conceptualiza como un Objeto Directo de FS Afectado. En ático clásico se marca mayoritariamente con el caso acusativo $^{3}$ y en la codificación en voz pasiva asciende a la posición de Sujeto (2b). Se trata de un Objeto poco prototípico, en la medida en que no es creado ni modificado por la acción principal, pero sí se ve afectado por ella: recibe la influencia que el Agente principal ejerce sobre él, como consecuencia de la cual se postula como Agente inmediato del evento que se quiere causar.

Por último, un tercer complemento define una situación o un evento no preexistente a la acción verbal, pero cuyo cumplimiento, o no, se espera como resultado de la intervención principal: hay, pues, una diferencia en el ámbito espacio-temporal entre la acción causante - previa - y el evento causado — posterior-. No es fácil identificar la FS de este término (Jiménez: 2003; 2007), por lo que aquí he optado por asignarle la etiqueta genérica de complementum efficiendum (Riaño, 2006: 209 ss.), que describe muy bien su contenido. Este complemento se codifica bien con un sintagma nominal en acusativo ${ }^{4}(2 \mathrm{c})$, bien con un infinitivo (sólo en el caso de $\pi \varepsilon i ́ \theta \omega$, como se verá en $\S 5$, es posible una subordinada conjuncional: cf. (2d) y (2e)).

\footnotetext{
${ }^{3}$ Excepcionalmente (cf. Riaño 2006: 440, 565 s.), en ático clásico cabe la posibilidad de que este segundo argumento adopte, en algunos de los verbos que aquí se va a estudiar, un papel semántico diferente que encubre una idea de separación, según indica su codificación en forma de sintagma preposicional

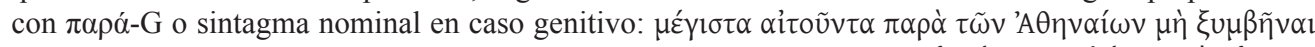

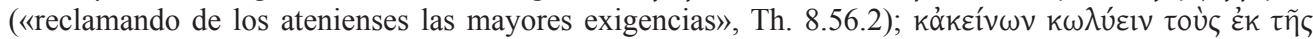

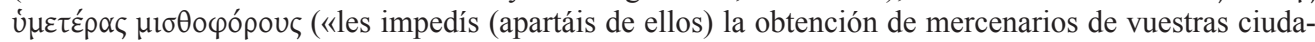
des», Th. 1.35.4). Un comportamiento idéntico tienen también estos verbos en español (Cano Aguilar, 1987: 346). El marco predicativo de (1) representa la estructura sintáctica básica o prototípica de estos predicados y da cuenta de la mayor parte de sus usos en un estadio sincrónico concreto, sin perjuicio de que puedan existir construcciones alternantes menos frecuentes (cf. Jiménez, 2003: 115, n. 10).

${ }^{4}$ Riaño (2006: 212-217) señala que cuando la acción es negativa el sintagma nominal puede construirse en caso genitivo. En el corpus analizado no he encontrado ningún ejemplo de este tipo.
} 
Mi objetivo en este trabajo es el estudio comparativo de las estructuras sintácticas de estos seis predicados en sus empleos como verbos de influencia. ${ }^{5}$ Aun dentro de la homogeneidad del grupo, el análisis de los datos que ofrecen los textos de época clásica pone de manifiesto diferencias en el comportamiento sintáctico de unos verbos y otros. En este artículo me propongo determinar la razón de tales diferencias y comprobar si guardan relación con factores como la animacidad de las entidades implicadas, su volición y capacidad de control, el mayor o menor nivel de coerción del causante sobre el causado, si la coerción es de tipo comunicativo o no..., factores todos ellos que se han revelado pertinentes para describir la causatividad en otras lenguas.

El corpus de este estudio supone, para el conjunto de los seis verbos analizados, un

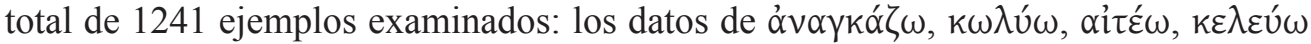
y żá $\omega$ corresponden a la obra completa de Lisias y Tucídides; los de $\pi \varepsilon i ́ \theta \omega$ incluyen, además, Jenofonte completo y cinco diálogos de Platón (Apología de Sócrates, Critón, Fedón, Banquete y Fedro).

\section{CONTINUUM CAUSATIVO}

Atendiendo al contenido semántico específico de cada uno de estos seis predicados, que aportan matices diferentes dentro de la idea genérica de causación, es posible definir en griego antiguo, al igual que en otras lenguas (cf. Alfonso 1998, Shibatini-Pardeshi, 2002), una escala de causación que va desde la expresión de un mayor grado de coerción hasta la coerción más mitigada o, utilizando los términos de Givón (2001: I,151 ss.; II: 44 ss.), un continuum que abarca desde los verbos implicativos a los no implicativos.

(3) Grado de coerción del Agente-causante

\begin{tabular}{|c|c|c|c|c|}
\hline coerción & & & & - coerción \\
\hline verbos implicativos & & & verbo & implicativ \\
\hline $\begin{array}{l}\text { obligación } \\
\text { positiva/negativa }\end{array}$ & persuasión & mandato & petición & permiso \\
\hline$v \alpha \gamma \kappa \alpha ́ \zeta \omega / \kappa \omega \lambda{ }^{\prime} \omega$ & $\pi \varepsilon i ́ \theta \omega$ & $\kappa \varepsilon \lambda \varepsilon u ́ \omega$ & 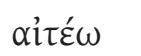 & $\varepsilon^{\prime} \alpha \omega_{\omega}$ \\
\hline
\end{tabular}

\footnotetext{
${ }^{5}$ En este sentido es necesario hacer una advertencia: el verbo żá $\omega$ presenta, junto a un marco predicativo triargumental (1)-(2h) y una semántica propios de un verbo de influencia con el significado dejar-permitir, un segundo marco predicativo $\left(\xi \dot{\varepsilon} \alpha \omega_{\mathrm{v}}{ }^{2}[/ \text { humano/ }]_{\text {Agente }}[/+/ \text {-humano/ }]_{\text {Afectado }}\right)$ que responde a un empleo dife-

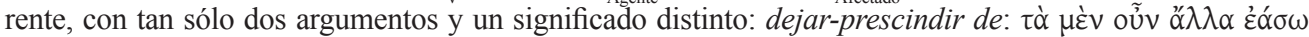
(«omitiré lo demás», Lys. 3.45). En estos usos éáw no es un verbo de influencia (Jiménez, 2003). También en $\pi \varepsilon i \theta \omega$ hay que reconocer en ático dos marcos predicativos diferenciados (Jiménez, 2007): el primero es el de su uso causativo como verbo de influencia (1)-(2d-e), en tanto que el segundo ( $\pi \varepsilon i ́ \theta \omega_{\mathrm{v}}{ }^{2}[/ \mathrm{hum} . /]_{\text {Agente-Afectado }}$ $[/ \text { hum. } /]_{\text {Beneficario }}[/ \text { situación/proposición/ }]_{\text {Fin/Referencia? }}$ ) pertenece básicamente a su empleo en voz media, con el

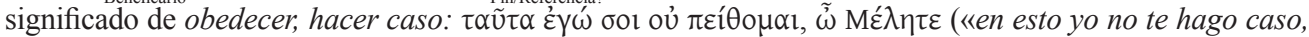
Meleto» (Pl. Ap. 25e). Los ejemplos correspondientes a estos usos quedan, pues, excluidos de este estudio.
} 
En el caso de los verbos de mayor grado de coerción o verbos implicativos, el hablante da por hecho que la intervención del causante tendrá como consecuencia necesaria el

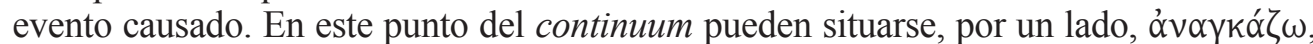
que denota una manipulación positiva: si es verdad la oración principal, también es verdad el complemento efficiendum; y, por otro, $\kappa \omega \lambda u ́ \omega$, que expresa una manipulación negativa: si es cierto lo que expresa el verbo principal, el complemento no tendrá lugar.

Hacia el otro lado de la escala, a medida que es menor la influencia que el causante ejerce sobre el causado, es progresivamente menor la expectativa de cumplimiento de la acción buscada. Cuando la coerción es más atenuada, la realidad del verbo principal no implica forzosamente la realización del complemento.

El esquema de (3) representa una escala gradual: no se pretende asignar a cada verbo un espacio estanco, ni colocarlo a una distancia exacta del verbo inmediatamente anterior o posterior. Se trata simplemente de un continuum en el que se sitúan, de forma relativa, los distintos predicados causativos-manipulativos en congruencia con los aspectos semánticos y sintácticos que se describen a continuación. Es posible también que determinados factores permitan que un verbo se desplace en este continuиm, como tendremos ocasión de ver.

\section{GRADO DE COERCIÓN DEL CAUSANTE Y DE AFECCIÓN DEL CAUSADO: FACTORES RELEVANTES}

El argumento que define al causado, y que en nuestros verbos se conceptualiza como Objeto Afectado, corresponde a una entidad humana que recibe la influencia ejercida por el causante con vistas a ser, a su vez, el Agente de la acción que se espera conseguir. Cabe plantearse, entonces, qué grado de agentividad, es decir, de independencia y, por tanto, de control, intención y voluntariedad tiene este término.

Una mayor coerción supone una mayor afección del causado y, en consecuencia, menor posibilidad de eludir la influencia de la que es objeto. Cuanto mayor es la coerción, menor es su independencia y, en este sentido, posee menor agentividad. Así sucede cuanto más a la izquierda de la escala (4) esté el verbo:

(4) Grado de afección y agentividad del Afectado-causado

+ coerción

- coerción

+ afección

- agentividad

verbos implicativos

obligación

positiva/negativa

$\grave{\alpha} v \alpha \gamma \kappa \alpha ́ \zeta \omega / \kappa \omega \lambda u ́ \omega$

persuasión mandato

verbos no implicativos

- afección

- agentividad

petición permiso

$\pi \varepsilon \dot{\theta} \theta \omega$

$\kappa \varepsilon \lambda \varepsilon \cup ́ \omega$

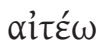

$\varepsilon \dot{\varepsilon} \omega$

Un ejemplo como (5a) no deja lugar a la duda: con $\alpha \dot{v} \alpha \gamma \kappa \alpha ́ \zeta \omega$ el causado es correferencial con el Sujeto del infinitivo $\pi$ orñ $\sigma \alpha$, pero realmente no presenta todos los 
rasgos que definen al Agente prototípico como la voluntariedad y el control total de la acción que llevará cabo con posterioridad. Igualmente (5b) refleja la falta de autonomía del Afectado de $\kappa \omega \lambda v ́ \omega$, ya que se anula su iniciativa. Con estos verbos el hablante tiene la máxima expectativa de que, independientemente de la voluntad e intención del causado-Afectado, tendrá lugar ( $\alpha$ va $\gamma \kappa \alpha ́ \zeta \omega)$ o no tendrá lugar ( $\kappa \omega \lambda \hat{u} \omega)$ el evento causado: la afección del Objeto es, por tanto, máxima y menor su agentividad.

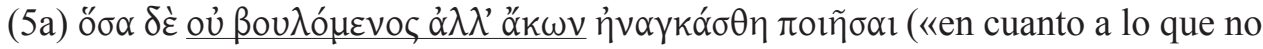
por propia voluntad, sino forzado se vio obligado a hacer», Lys. 18.25)

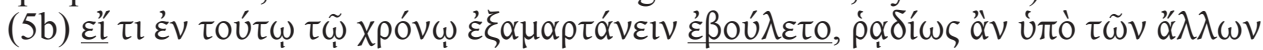
$\varepsilon \dot{\kappa} \omega \lambda u_{\text {écto ( }}$ (aunque hubiera querido cometer un delito en ese tiempo, habría sido impedido por los demás fácilmente», Lys. 26.11.4)

A medida que se avanza hacia la derecha la expectativa de cumplimiento va disminuyendo porque también disminuye la afección del causado y éste puede someterse o no a la influencia de la que es objeto, es decir, tiene mayor margen de agentividad.

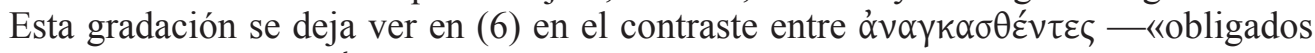

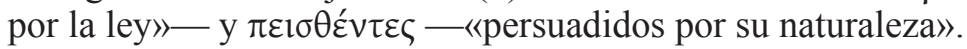

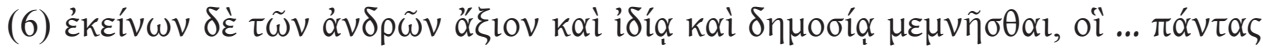

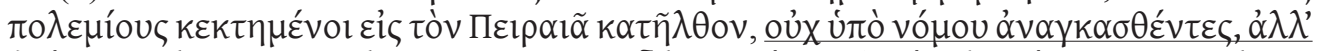

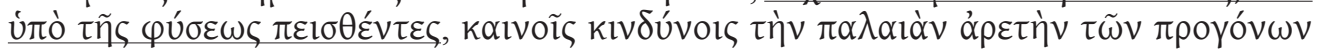
$\mu \nmid \mu \eta \sigma \alpha ́ \mu \varepsilon v o l$ («es justo recordar tanto en público como en privado a aquellos hombres que ... teniendo a todos por enemigos, regresaron al Pireo, no obligados por la ley, sino persuadidos por su naturaleza, por imitar la antigua virtud de sus antepasados en nuevos peligros», Lys. 2.61.7)

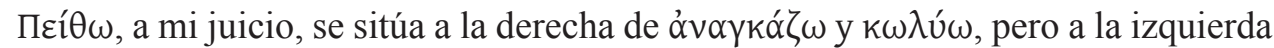
de los demás verbos: por un lado, es un verbo fuertemente implicativo. Así, en Juan persuade/convence a María de que salga con él, si es verdad la primera parte - Juan verdaderamente persuade/convence a María -, es verdad también la segunda parte - María sale realmente con Juan-. Esto, en cambio, no sucede con los restantes predicados, porque son menos implicativos: en Juan ordena/pide/permite a María que salga con él, si es verdad la acción principal — Juan verdaderamente ordena/pide/permite a María - , no se infiere necesariamente la realización del complemento: María puede salir o puede no salir con Juan.

Por otro lado, algunos ejemplos del corpus como (7a) muestran que la coerción de la persuación sobre el causado puede contar con la voluntad de éste $(\pi \rho 0 \theta u ́ \mu \omega \varsigma)$ o

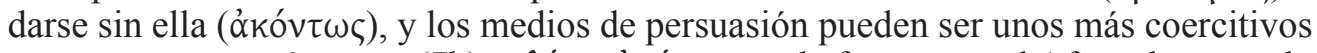

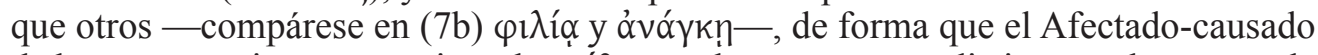
de las construcciones causativas de $\pi \varepsilon i ́ \theta \omega$ puede presentar, en distinto grado, rasgos de voluntariedad y control propios de un Agente. Esto significa que en la representación formal del continuum, $\pi \varepsilon i ́ \theta \omega$ puede desplazarse en su espacio más a la izquierda o a la derecha en función de estos factores. 


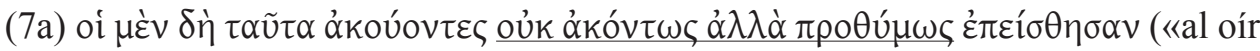
esto se dejaron persuadir no contra su voluntad sino de buena gana» X. HG. 4.8.5)

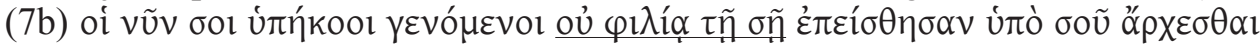

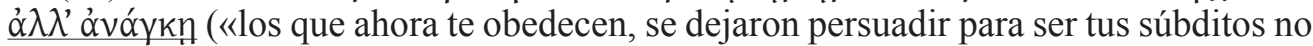
por amistad a ti, sino por necesidad», X. An. 7.7.29)

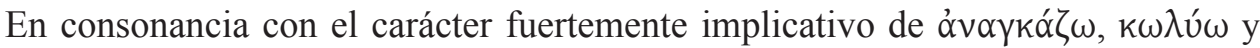
$\pi \varepsilon i ́ \theta \omega$ se observa el siguiente hecho: aunque en los tres prevalece como primer argumento el Agente prototípico humano, pueden también llevar como Sujeto entidades no humanas (en nuestro corpus, un 3\%,13\% y 1,9\%, respectivamente) que denotan una Fuerza coercitiva indudable: así, la magnitud de las desgracias de (8a), el viento de (8b) o el interés y el miedo de (8c) son Actores causantes a cuya influencia difícilmente puede sustraerse el Afectado causado. El tipo de entidad (humana o no humana) que define el primer argumento es otro factor relevante en el grado de coerción y, por tanto, en la posición que los verbos ocupan en el continuum.

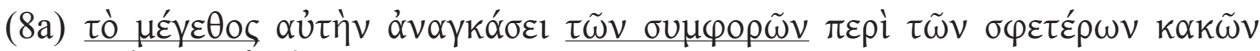

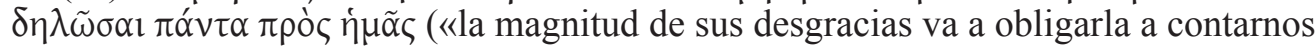
todo sobre sus males», Lys. 32.11)

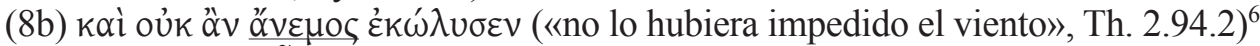

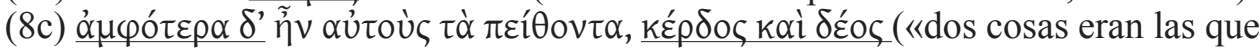
les persuadían, el interés y el miedo», Lys. 2.29.8)

Así, menor fuerza coercitiva y afección del Afectado, pero todavía en un grado elevado presupone $\kappa \varepsilon \lambda \varepsilon v ́ \omega$ : la influencia que recibe el causado para la realización del evento es grande, pero tiene cierta capacidad de control sobre el complemento

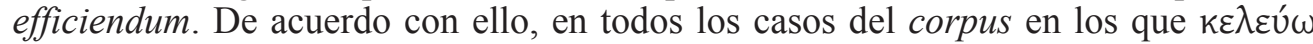

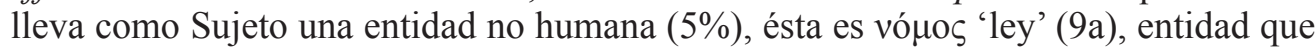
se supone ejerce una cierta coerción sobre el Afectado, pero no anula absolutamente su voluntad, ya que no es inusual contravenir las leyes.

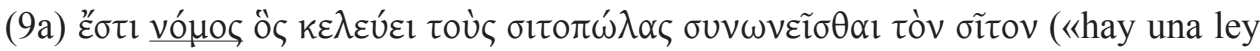
que prescribe a los vendedores de trigo comprarlo conjuntamente», Lys. 22.6)

Por otra parte, con frecuencia el complemento Afectado de $\kappa \varepsilon \lambda \varepsilon u ́ \omega$ es una persona en una posición social, jerárquica o circunstancialmente inferior, de modo que para ella es difícil escapar a la influencia del Agente-causante, como la esclava de (9b) o el propio Lisias en $(9 \mathrm{c})$ cuando es apresado por un grupo de los Treinta. A veces, sin embargo, no existe una diferencia jerárquica entre ellos, como sucede en (9d) en la invitación a cenar de Eufileto a su amigo, o se presenta mitigada, lo que aumenta la autonomía y control del causado, como en (9e).

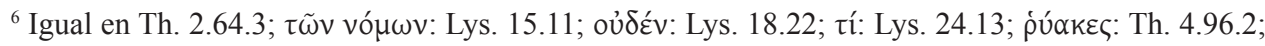

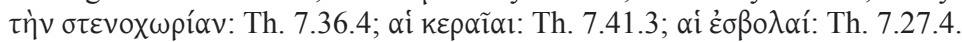




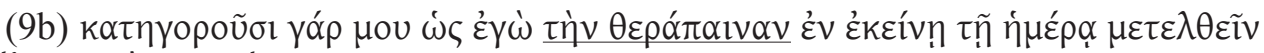

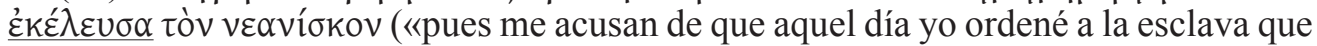
fuera a buscar al joven», Lys. 1.37.2)

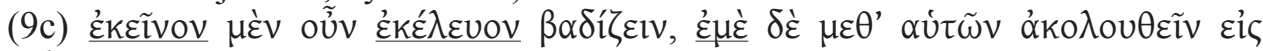
$\Delta \alpha \mu v i ́$ trov («ordenaron a aquel que se fuera y a mí que los siguiera a casa de Damnipo», Lys. 12.12.6)

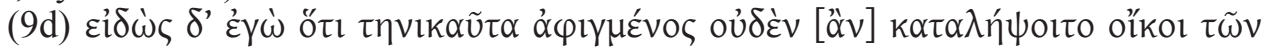

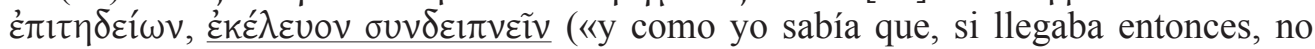
encontraría en casa a ningún pariente, le invité a cenar conmigo», Lys. 1.22.8)

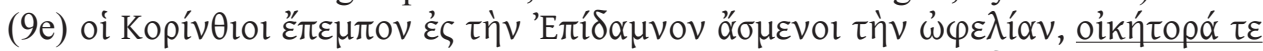

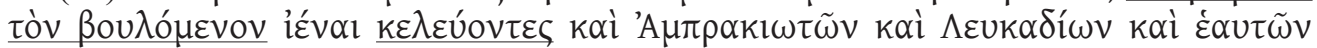

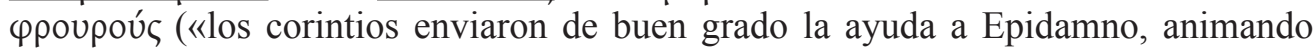
a que fueran los colonos que quisieran y una guarnición de ampraciotas, leucadios y corintios», Th. 1.26.1)

En consecuencia, $\kappa \varepsilon \lambda \varepsilon u ́ \omega$ puede desplazarse en el continuum causativo hacia la derecha o hacia la izquierda en función de otro factor pertinente como es la relación jerárquica del causante y el causado. Así, la primera vez que se usa $\kappa \varepsilon \lambda \varepsilon u ́ \omega$ en (9f) el marido aspira a influir sobre su esposa desde un plano pretendidamente de igualdad, por lo que ésta puede resistirse —el Afectado tiene aquí más rasgos agentivos-, pero la segunda vez se sitúa claramente en una posición jerárquica superior y ella ya no puede desobedecer - la afección es mayor y mayor también la expectativa de cumplimiento del complemento efficiendum- Esta posibilidad de desplazarse en la escala de causatividad se manifiesta, en fin, en la gama de acepciones que recogen los diccionarios para este verbo: 'animar, exhortar, ordenar, mandar, aconsejar, exigir, pedir'.

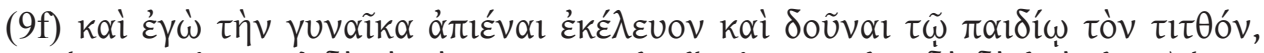

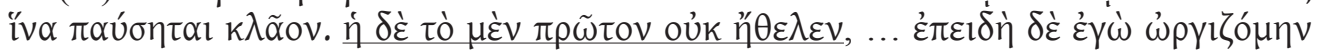

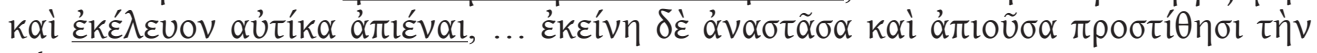
Өúpav, («y yo pedí a mi mujer que saliera y diera el pecho al niño, para que dejara de llorar. Ella al principio no quería..., pero cuando me enfadé y le ordené que fuera inmediatamente ... ella se levantó y, saliendo, cerró la puerta», Lys. 1.12.3)

Por su parte, con $\alpha i \imath \varepsilon ́ \omega$ la afección del causado es menor y, por tanto, mayor su independencia y capacidad de control sobre la ejecución del complemento efficiendum: puede negarse abiertamente a realizar lo que se le pide, como sucede en (10).

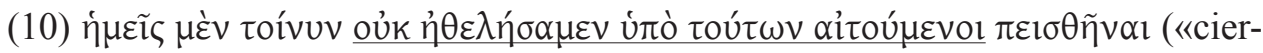
tamente no quisimos hacerles caso cuando nos lo pedían», Lys. 30.35.2)

La posición que aiıź $\omega$ ocupa en el continuum de causatividad permite entender las diferencias semánticas y sintácticas de este verbo con respecto a los demás del grupo $\mathrm{y}$, en particular, con respecto a un predicado semánticamente próximo como

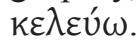


Así, el carácter más coercitivo de este último explica la posibilidad de llevar como

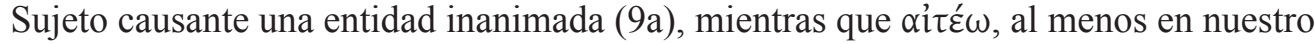
corpus, sólo lleva como Sujeto una entidad humana.

Por otra parte, $\kappa \varepsilon \lambda \varepsilon \cup ́ \omega$, como los otros verbos del grupo estudiado, construye siempre su tercer argumento con entidades de segundo orden: este complemento - codificado mayoritariamente en infinitivo (9) y ocasionalmente (sólo un 3\%) en acusativo (11a) - no es preexistente a la acción verbal, sino que su realización se espera como

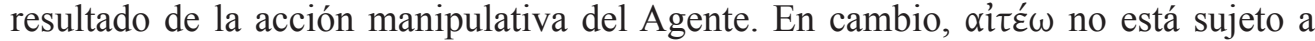
esta restricción: además de admitir como complemento efficiendum una entidad de segundo orden (11b) (22a), cuyo cumplimiento es posterior a la petición, su uso más extendido (un $89 \%$ en nuestro corpus) es con una entidad de primer orden, codificada con un nombre en acusativo, que es preexistente a la acción verbal: así, ni el dinero de (11c) ni Lisandro en (11d) son resultado de la acción causativa, porque existen previamente a ella. Aunque puede entenderse una idea sincopada o metonímica (asimismo, Riaño 2006: 204) —en (11c) el Agente «pide a Tisafernes [que le dé] dinero» o en (11d) «pide [que le concedan] a Lisandro como jefe»-, lo importante es que esta

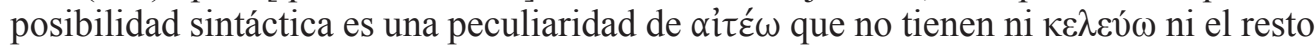
de verbos de influencia del grupo estudiado.

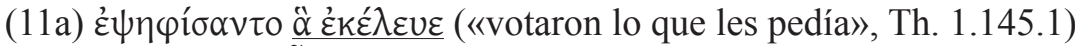

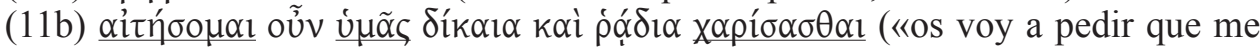
concedáis un favor justo y fácil», Lys. 19.2)

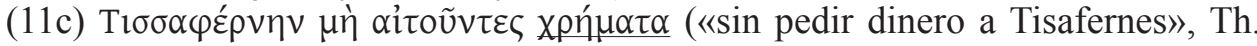
$8.44 .1)$

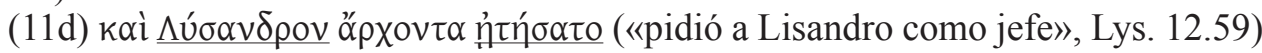

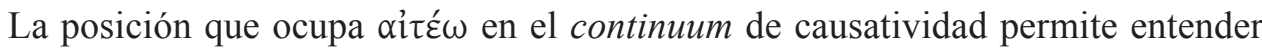
otro uso específico de este verbo, que atiende a la siguiente distribución: cuando se explicita el complemento Afectado - v́rús en (11b) - es porque esta entidad es correferencial con el Sujeto del infinitivo: es la persona que se espera realice la acción causada («os pido a vosotros que [vosotros] me concedáis un favor»). Pero cuando no se explicita el término que define el causado, i.e. el acusativo de persona (11e-f), lo que hay que entender es que el Agente pide a alguien implícito en el contexto que le permita al propio Agente realizar la acción causada: por ejemplo, en (11f) «nosotros no habríamos pedido [a la asamblea] hablar [nosotros]»). En este uso, pues, la coerción sobre el Afectado implícito es mínima y es el Agente causante el que, prácticamente, se subordina a la voluntad de aquel para llevar a cabo el complemento efficiendum.

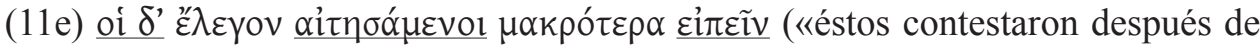
haber pedido hablar más extensamente», Th. 3.52.5)

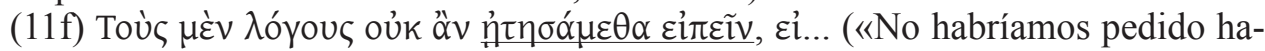
blar, si...», Th.3.61.1) 
En conclusión, pues, la variedad de estructuras sintácticas que presenta en griego

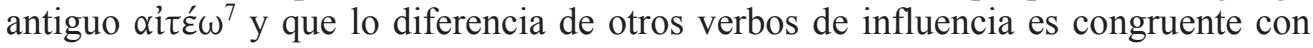
su posición en el continuum causativo, en virtud de sus rasgos de menor coerción del causante y menor afección del causado.

Por último, con żóc el Sujeto causante manifiesta su voluntad de no impedir al Objeto Afectado que lleve a cabo determinada acción, algo que — se da por sentado - estaría en condiciones de hacer si quisiera. El causado se ve, por tanto, afectado por la influencia del causante, pero, en última instancia, se le otorga la capacidad de actuar o no y, en consecuencia, presenta mayor grado de agentividad. Normalmente cabe esperar el cumplimiento posterior del complemento efficiendum, en la medida en que la concesión de permiso por parte del Agente presupone una voluntad previa del Afectado de llevar a cabo esa acción (12a).

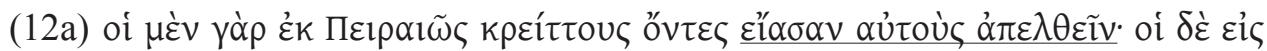

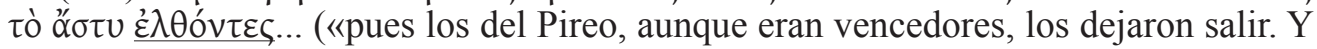
éstos se dirigieron a la ciudad...», Lys. 12.54.1)

En el caso de çác $\omega$ otro factor confirma su posición en el continuum descrito: la negación. Cuando żów está negado (12b) se comporta como un verbo implicativo negativo (oủk żów $\omega=\kappa \omega \lambda u^{\prime} \omega$ ): se da por seguro que la influencia del Agente-causante hará que el Afectado no lleve a cabo el complemento efficiendum. La presencia o ausencia de negación es, pues, un elemento determinante en su posición en el polo izquierdo o derecho del continuum causativo. ${ }^{8}$

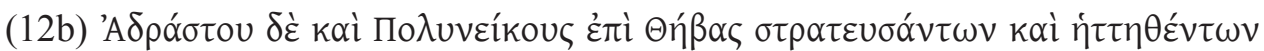

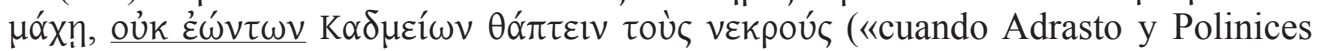
fueron en expedición contra Tebas y fueron vencidos en combate, los cadmeos no les permitieron enterrar a sus muertos», Lys. 2.7)

En consonancia con los factores que hemos ido viendo hasta aquí, çác se construye mayoritariamente con un Sujeto causante humano (la concesión de permiso a un causado para que realice algo implica la consciencia, voluntariedad y control de una entidad humana), pero en los pocos casos (en el corpus, 5,4\%) en que su Sujeto es inanimado —o es vópoৎ (12c) o bien un único caso como (12d) — żác siempre va negado. No es una casualidad: es entonces cuando se comporta como un verbo implicativo y fuertemente coercitivo y, de la misma forma que $\kappa \omega \lambda \hat{v} \omega$, es compatible con un Sujeto causante no humano, más coercitivo.

\footnotetext{
${ }^{7}$ Coincide en todo con los usos y la descripción que se ha hecho en español para el verbo pedir (Cano Aguilar, 1987: 145-7; 351-352).

${ }^{8}$ El empleo negado de $\varepsilon_{\alpha} \alpha ́ \omega$ es mayoritario en el corpus estudiado (56,3\%) frente a lo que sucede con los demás verbos. K $\omega \lambda \hat{u} \omega$, por ejemplo, sólo se niega en un 17,8\% de las ocasiones; en él la negación atenúa la fuerza coercitiva del Agente-causante y aumenta los rasgos agentivos del Afectado-causado, con lo que se aproxima al polo opuesto del continuum, hacia los verbos no implicativos.
} 


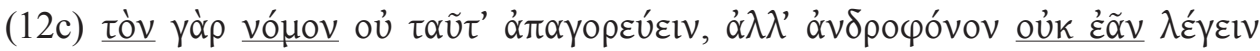
(«pues la ley no prohibe eso, sino que no permite llamar asesino a nadie», Lys. 10.6)

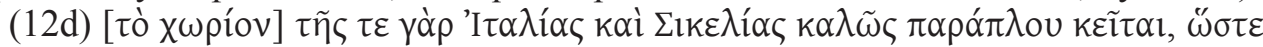

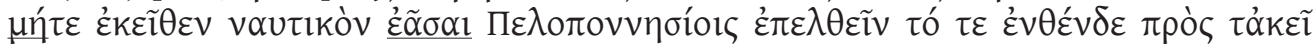

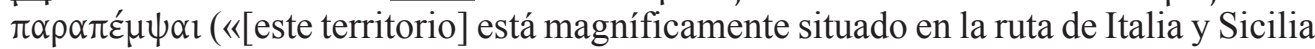
como para no permitir a ninguna flota venir desde allí en ayuda de los peloponesios y dejar pasar la de aquí hacia allí», Th. 1.36.2)

\section{VERBOS DE INFLUENCIA Y COMUNICACIÓN VERBAL}

Otro aspecto que resulta relevante a la hora de entender las diferencias entre nuestros verbos es la naturaleza de la influencia ejercida por el Agente-causante sobre el Afectado-causado. Los datos de nuestro corpus muestran que algunos de estos verbos implican comunicación verbal y otros no ${ }^{9}$ y que este hecho es coherente con la posición que cada uno ocupa en el continuum causativo descrito en (4): la coerción ejercida mediante la palabra es menor que la que pueda darse por otros medios.

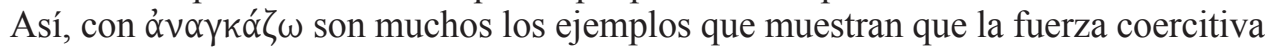
se ejerce con recursos más drásticos que la simple palabra (13a-b), lo que corresponde a un verbo fuertemente implicativo, situado en el extremo izquierdo del continuum.

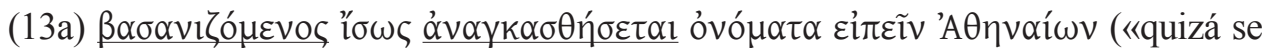
verá obligado bajo tortura a decir los nombres de los atenienses...», Lys. 13.25)

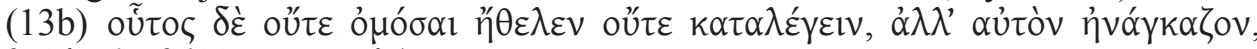

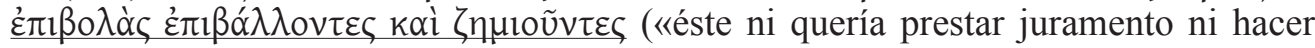
una lista, pero le obligaron imponiéndole multas y castigándole», Lys. 20.14)

Lo mismo sucede con $\kappa \omega \lambda u ́ \omega:$ en (19a) se constata que este verbo no presupone necesariamente comunicación verbal, de ahí que en (19b) sea necesario añadir el participio $\varphi \alpha ́ \sigma \kappa o v \tau \alpha \varsigma$ con su completiva correspondiente para entender que la influencia se ejerce con argumentos y no con otro tipo de medios.

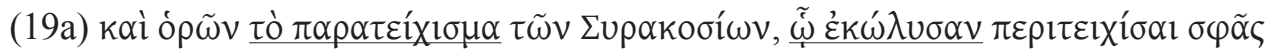

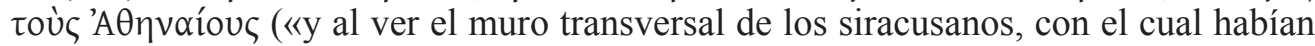
impedido a los atenienses cerrarles el cerco», Th. 7.42.4)

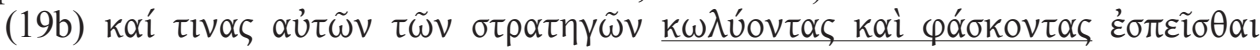

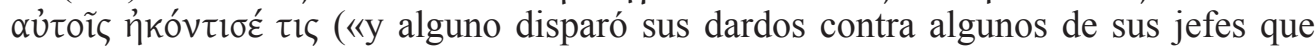
trataban de impedir [la persecución a los peloponesios] y decían que se había hecho un pacto con ellos», Th. 3.111.3)

\footnotetext{
${ }^{9}$ Givón (2001: 41 ss.) propone un continuum semántico que iría desde los verbos manipulativos a los cognitivo-declarativos. Recuérdese que los verbos estudiados se han clasificado en las gramáticas griegas de forma diversa: por ejemplo, Schwyzer (1950: 376) incluye los verbos que significan ordenar y prohibir entre los verba dicendi, en tanto que Kühner-Gerth (1904, II.2: 6) recogen $\kappa \omega \lambda \hat{\omega} \omega, \pi \varepsilon i ́ \theta \omega, ~ \kappa \varepsilon \lambda \varepsilon v ́ \omega$ y

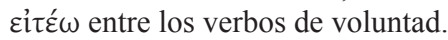


Con $\pi \varepsilon^{i} \theta \omega$, ya lo hemos visto, el Sujeto causante puede ser una entidad inanimada como 'el interés' o 'el miedo' en (8c), de modo que no siempre hay implícita una comunicación verbal entre causante y causado y, en otros casos, se indica que es el dinero el instrumento de persuasión (20a)-(20b). Sin embargo, a diferencia de los dos verbos anteriores, no es extraño encontrar ejemplos en los que aparece un participio predicativo concertado con el sujeto del tipo de $\lambda \varepsilon ́ \gamma \omega \nu$ en (20c-d) o un dativo ins-

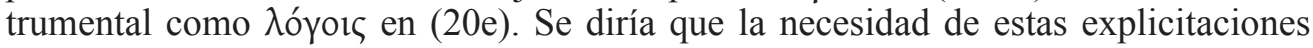
se debe a que $\pi \varepsilon i ́ \theta \omega$ no implica necesariamente una forma de coerción mediante la palabra, pero es frecuente que así sea, lo que se compadece bien con su posición en el continuum de coerción y afección descrito en (4).

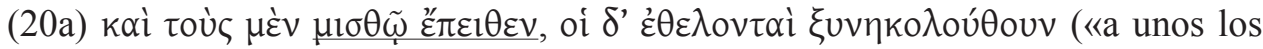
persuadió con una soldada, y otros lo siguieron voluntariamente», Th. 2.96.2)

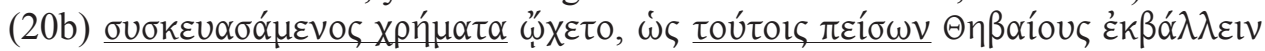

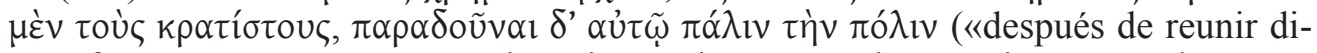
nero fue a convencer con este a los tebanos de que expulsaran a los más poderosos», X. $H G$. 7.3.4)

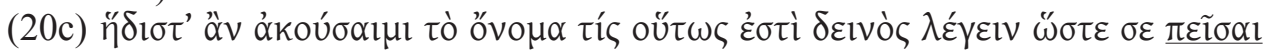

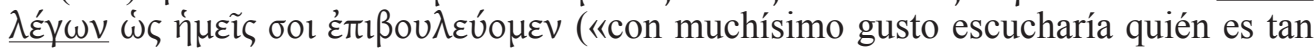
hábil en hablar que, hablando, te ha convencido de que nosotros conspiramos contra ti», X. An. 2.5.15)

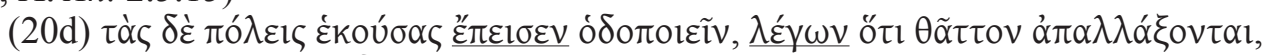

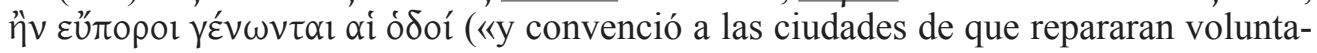
riamente los caminos diciendo que se marcharían más rápidamente si los caminos eran accesibles», X. An. 5.1.14)

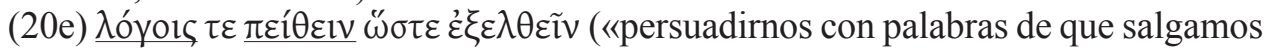
de la ciudad», Th. 3.66.2)

En cambio, $\kappa \varepsilon \lambda \varepsilon u ́ \omega$ sí conlleva siempre que la influencia del causante sobre el causado se establece mediante comunicación verbal: así, son frecuentes los casos como (21a) en los que, al no estar próximos causante y causado, se envía un mensajero para transmitir la orden o petición, o se hace ver que el intercambio comunicativo

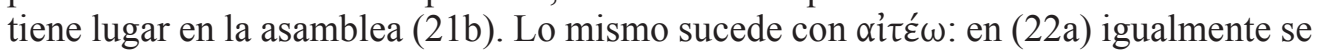
requiere la presencia de un heraldo para transmitir verbalmente la petición. La diferencia entre estos dos verbos y los tres anteriores es que ambos son verbos realizativos o performativos, ya que transmiten un acto de habla de fuerza ilocutiva directiva o impresiva, como ilustra bien (22b), en el que el participio define el tipo de acto ilocutivo

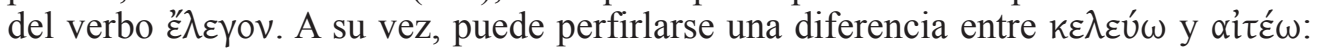
con el primero el Sujeto-causante es mayoritariamente una entidad humana y, cuando no es así, se trata siempre - ya lo hemos visto - del nombre vó $\mu$ os (9a), para el que cabe una interpretación metonómica por los legisladores; en cambio, aiıź $\omega$ sólo es

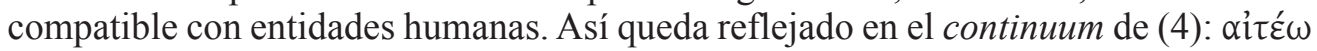
se sitúa más a la derecha que $\kappa \varepsilon \lambda \varepsilon v ́ \omega$, pues el grado de coerción de su Sujeto-causante es menor. 


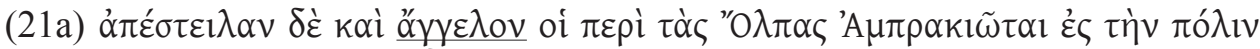

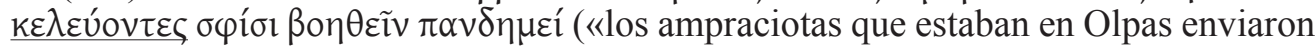
también un mensajero a su ciudad pidiendo que les ayudaran con todas sus fuerzas», Th. 3.105.4)

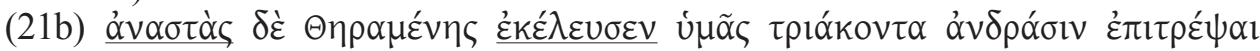

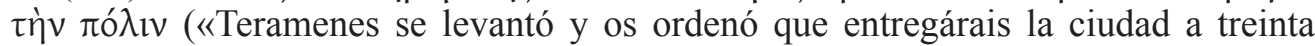
hombres», Lys. 12.73)

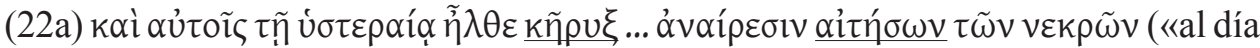
siguiente les llegó un heraldo... para pedir la retirada de los cadáveres», Th. 3.113.1)

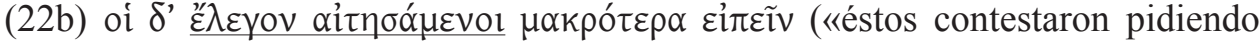
poder hablar más extensamente», Th. 3.52.5)

Por lo que respecta a żó́ $\omega$, así como en español se considera que permitir o dejar pueden usarse como verbos realizativos (Moreno Cabrera, 2000:II, 353 ss.), en la idea de que te permito salir puede formalizarse también con un imperativo - isal! - , los datos del corpus analizado no son concluyentes en este sentido para el verbo griego:

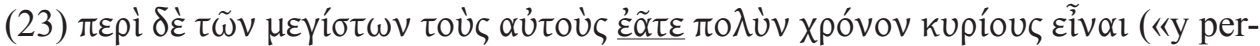
mitís que los mismos hombres tengan autoridad sobre los asuntos más importantes durante mucho tiempo», Lys. 30.29.3)

\section{COMPATIBILIDAD CON عĩvaı y $\gamma \dot{\imath} \gamma v \varepsilon \sigma \theta \alpha \iota$}

Por la propia naturaleza de los verbos causativos, el complemento efficiendum ha de ser una Acción, controlada por el causado, sobre el que se trata de influir para que la lleve a cabo. Desde esta perspectiva, no serían esperables ejemplos en los que este complemento fuera un estado o situación no controlada: no se puede decir *te obligo/ te impido/te ordeno/te pido que seas guapo, *te obligo/te impido/te ordeno/te pido que tengas 20 años. Por lo tanto, en griego cabría pensar que los verbos objeto de este estudio serían reticentes a construirse con eĩval. Y así es: los cuatro ejemplos de (24) son los únicos que se documentan con $\kappa \omega \lambda \hat{\omega} \omega, \kappa \varepsilon \lambda \varepsilon u ́ \omega$ y $\varepsilon$ á $\omega$ en toda la obra de Lisias

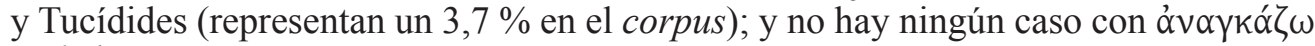
y $\alpha i \tau \varepsilon \dot{\varepsilon} \omega$.

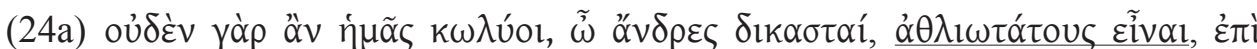

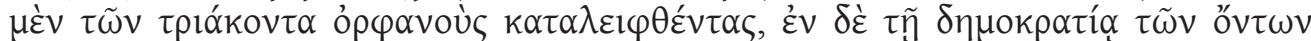

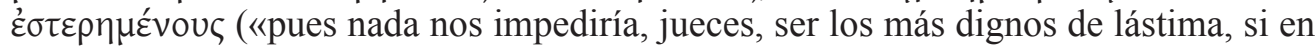
tiempos de los Treinta quedamos huérfanos y en democracia se nos priva de nuestros bienes», Lys. 18.22.1)

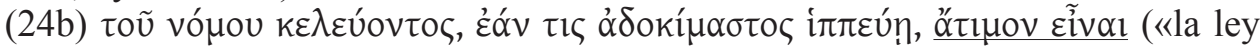
ordena que, si uno sirve en la caballería sin pasar examen, sea privado de los derechos de ciudadanía», Lys. 14.8.5) 


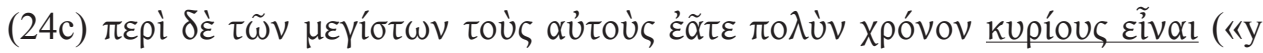
permitís que los mismos hombres tengan autoridad sobre los asuntos más importantes durante mucho tiempo», Lys. 30.29.3)

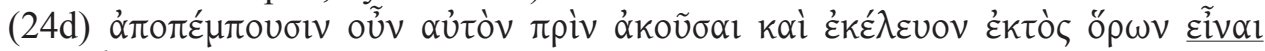

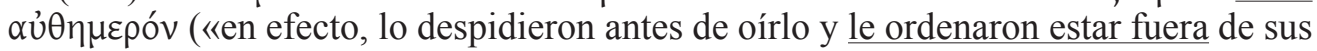
fronteras ese mismo día», Th. 2.12.2)

Estos ejemplos son posibles porque, en realidad, en ellos عĩvol no define un estado, sino casi un proceso, en la medida en que se expresa no una cualidad esencial, inherente o permanente, sino más bien una cualidad circunstancial o adquirida temporalmente como en (24a)-(24c) o incluso una posición como en (24d).

Precisamente esta razón ayuda a entender por qué es algo mayor con estos verbos

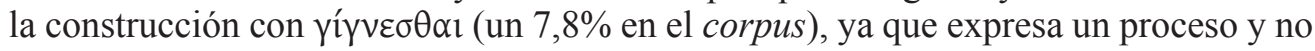
un estado:

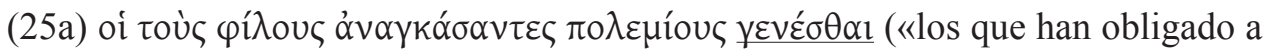
sus amigos a convertirse en enemigos», Th. 6.92.3)

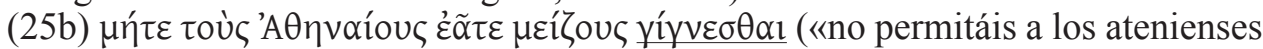
hacerse más poderosos», Th. 1.86.5)

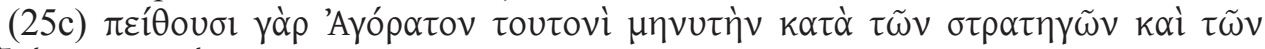

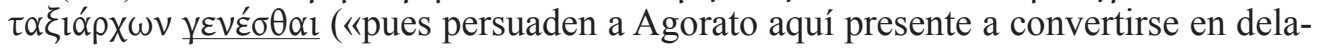
tor de los generales y taxiarcos», Lys. 13.18.1)

No he mencionado hasta aquí el caso de $\pi \varepsilon i ́ \theta \omega$, pues requiere una atención especial. En efecto, en ejemplos como los de (26), se documenta como tercer constituyente de su estructura sintáctica el verbo eĩval con valor copulativo y con atributos que expresan propiedades o cualidades inherentes y permanentes de sus respectivos sujetos.

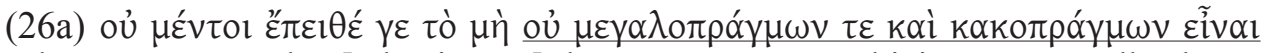
(«no logró convencerlos [a los jueces] de que no era un ambicioso y un malhechor», X. $H G$ 5.2.36)

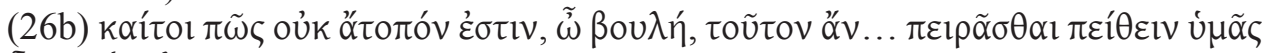

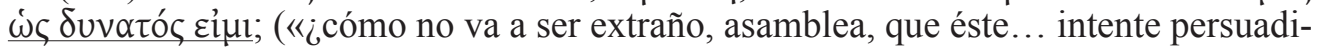
ros de que soy capacitado?», Lys. 24.12)

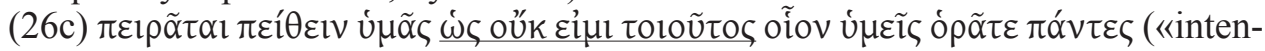
ta convenceros de que yo no soy tal cual todos vosotros véis», Lys. 24.14)

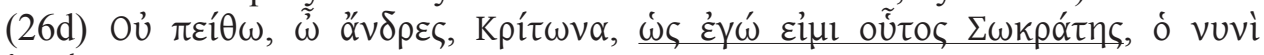
$\delta 1 \alpha \lambda \varepsilon \gamma o ́ \mu \varepsilon v o \varsigma$ ( «no logro persuadir a Critón, amigos, de yo soy ese Sócrates que conversa ahora con vosotros», $\mathrm{Pl}$. Phd. 115c)

Pero no es este el único rasgo que diferencia estos ejemplos de los de (24) y (25): (I) en primer lugar, se observará que en ningún ejemplo de (26) el tercer complemento se codifica como infinitivo del tipo que en griego suele llamarse dinámico, que es el que se da en (24) y (25): en (26a) aparece un infinitivo declarativo y en los demás ejemplos hay una subordinada conjuncional. (II) Pero, además, el Objeto-causado, explícito o 
implícito, no es correferencial con el Sujeto del verbo eỉuí: en (26c), por ejemplo, «no queriendo persuadiros a vosotros de que yo soy así». (III) Más aún, la situación que refiere este término no se cumple necesariamente con posterioridad a la acción de persuadir, sino que, como sucede en todos los ejemplos citados, puede ser simultánea o anterior. (Iv) Además, la intención ilocutiva de los ejemplos de (26) es declarativa, frente a la fuerza ilocutiva impresiva de los ejemplos anteriores.

Todas estas características indican que los ejemplos de (26) corresponden, en realidad, a un segundo uso de $\pi \varepsilon i ́ \theta \omega$ que dota a este verbo de una particularidad que no comparte el resto de verbos de influencia estudiados. En efecto, $\pi \varepsilon i ́ \theta \omega$ tiene dos usos causativos diferentes (Jiménez, 2007): en empleos como los de (27a) $\pi \varepsilon i ́ \theta \omega$ lleva como tercer argumento una entidad de segundo orden y se codifica mediante una construcción de infinitivo de los llamados dinámicos; en estos casos se comporta sin-

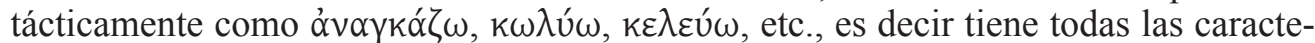
rísticas que hemos descrito como comunes para los verbos causativos de influencia: en esta construcción, causativa factitiva, significa persuadir a alguien a hacer algo. En cambio, en usos como los de (27b), que he llamado causativos cognitivos, el tercer constituyente define una proposición y ésta se codifica con una construcción de infinitivo declarativo (Ac.Inf.) o mediante subordinada conjuncional; en estos casos $\pi \varepsilon i ́ \theta \omega$ significa persuadir a alguien a creer algo. En definitiva, la acción causativa de $\pi \varepsilon i ́ \theta \omega$ está siempre encaminada a lograr algo del causado, pero mientras en el primer caso es que realice determinada acción, en el segundo es que admita la verdad de la proposición. Pues bien, en nuestro corpus todos los usos de عĩval con $\pi \varepsilon i ́ \theta \omega$ se dan en el empleo causativo cognitivo (26), que es compatible con el sentido plenamente copulativo de este verbo, puesto que se trata de proposiciones.

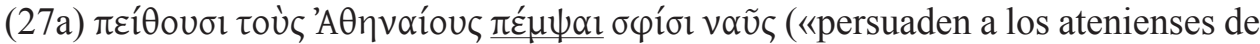
que les envíen naves», (Th. 3.86.3)

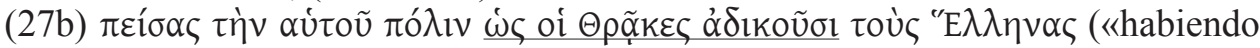
persuadido a su ciudad de que los tracios agraviaban a los helenos», X. An. 2.6.2)

\section{CONCLUSIÓN}

El estudio de un grupo de verbos que expresan causación indirecta y que suelen de-

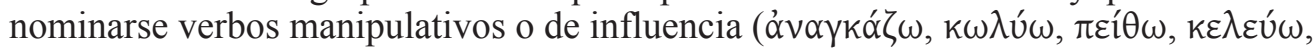

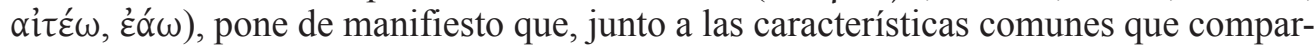
ten, hay aspectos semánticos y sintácticos en que difieren. En este trabajo he tratado de mostrar que algunas de esas diferencias y comportamientos sintácticos específicos de cada verbo pueden entenderse dentro de un continuum de causatividad que, en función del mayor o menor grado de coerción ejercido por el causante sobre el causado y de la mayor o menor afección de este, permite situarlos en una escala (4) que va de los verbos implicativos a los no implicativos.

En este sentido se han mostrado pertinentes factores diversos como la animacidad o no de la entidad del causante, la relación de tipo jerárquico que exista entre causante 
y causado, la presencia o ausencia de negación, el medio con el que se ejerce la influencia. Se han puesto de manifiesto, también, otros aspectos distintivos como el carácter de verbos realizativos o performativos de algunos de estos predicados ( $\kappa \varepsilon \lambda \varepsilon v ́ \omega$,

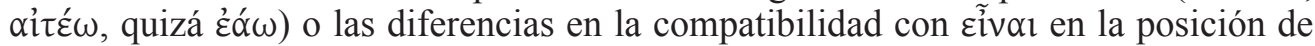
complemento efficiendum. Se ha visto, además, que la posición que un verbo ocupa en el continuum de causatividad no es fija, sino que hay factores por los que puede desplazarse más a la derecha o a la izquierda y ser, por lo tanto, más o menos implicativo.

Si se acepta la pertinencia de un continuum causativo para describir los verbos de influencia en griego antiguo, sería posible, quizá, situar en esta escala otros predica-

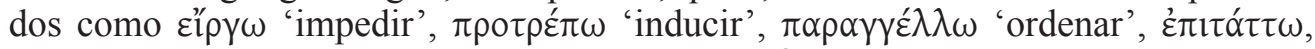

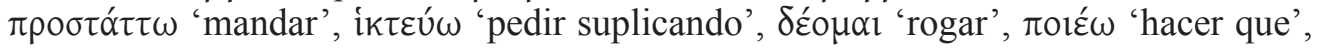
y avanzando en el continuum hacia una menor coerción otros predicados de permi-

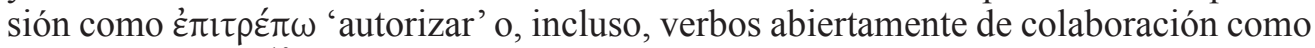
$\beta o \eta \theta \dot{\varepsilon} \omega$ 'ayudar' ${ }^{10}$ y otros semejantes.

\section{REFERENCIAS BIBLIOGRÁFICAS}

Alfonso Vega, Milagros (1998), Construcciones causativas en el español medieval, México: Universidad Nacional Autónoma.

Allan, Rutger J. (2003), The middle voice in ancient Greek. A study in polysemy, Amsterdam: Gieben.

CAmpos, Héctor (1999), «Transitividad e intransitividad» en I. Bosque - V. Demonte (eds.), Gramática descriptiva de la lengua española, Madrid: Espasa, 1520-1574.

CANo Agullar, Rafael (1987), Estructuras sintácticas transitivas en el español actual, Madrid: Gredos.

Diк, Simon C. (1997), The Theory of Functional Grammar, ed. K. Hengeveld, Berlín-Nueva York: Mouton de Gruyter.

DowTY, David (1991), «Thematic Proto-roles and Argument Seletion», Language 67, 3: 547619.

Givón, Talmy (2001), Syntax. An Introduction, Amsterdam-Philadelphia: Benjamins.

Givón, Talmy - Young, Phil (2002), «Cooperation and interpersonal manipulation in the society of intimates», en M. Shibatani (ed.), 23-56.

KüHNER, Raphael - GERTH, Bernhard (1904³), Ausführiliche Grammatik der griechischen Sprache, Teil II: Satzlehre, 2 vols., Hannover: Hahnsche Buchhandlung.

JimÉnEZ LóPEZ, Ma Dolores (2003), «Estructuras sintácticas de los verbos de influencia» en J.M. Baños Baños et alii (eds.), Praedicativa. Complementación en griego y latín, Verba, anexo 53, Universidad de Santiago de Compostela, 111-137.

- (2007), «Persuadir en griego: el marco predicativo de $\pi \varepsilon i ́ \theta \omega »$ en E. Crespo - J. de la Villa - A. Revuelta (eds.), Word Classes and Related Topics in Ancient Greek. Proceedings of the Conference on 'Greek Syntax and Word Classes' held in Madrid on 18-21, June 2003,

${ }^{10}$ Shibatani y Pardeshi (2002) hablan de una 'causación sociativa' cuando el causante realiza la misma acción que el causado en el evento resultante. 
Bibliothèques des Cahiers de l'Institut de Linguistique de Louvain, Louvain-la-Neuve: Peeters, 163-191.

Moreno CABrera, Juan Carlos $\left(2002^{2}\right)$, Curso universitario de lingüística general, I-II Madrid: Síntesis.

RiAÑo, Daniel (2006), El Complemento Directo en griego antiguo, Madrid: C.S.I.C.

RiJKsBARON, Albert $\left(2002^{3}\right)$, The syntax and semantics of the verb in classical Greek. An Introduction, Amsterdam: Gieben.

Schwyzer, Eduard - DebrunNer, Albert (1950), Griechische Grammatik, München.

ShiBAtAni, Masayoshi (ed.) (2002), The grammar of causation and interpersonal manipulation, Amsterdam: Benjamins.

Shibatani, Masayoshi - Pardeshi, Prashant (2002), «The causative continuum», en M. Shibatani (ed.), 85-126.

Van Valin, Robert D. - LaPolla, Randy J. (1997), Syntax Structure, meaning and function, Cambridge: CUP. 